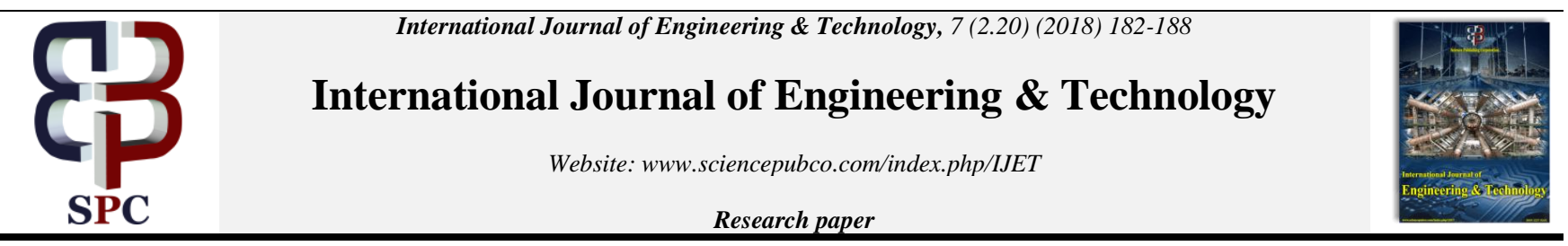

\title{
Investigation of Beam Column Joint with Beam Weak in Shear under Monotonic Loading
}

\author{
B. Mounika ${ }^{1 *}$, P. Poluraju ${ }^{2}$ \\ ${ }^{1}$ P.G student, Koneru Lakshmaiah Education Foundation, Guntur-52202. \\ ${ }^{2}$ Associate Professor, Koneru Lakshmaiah Education Foundation, Guntur-52202. \\ *Corresponding author E-mail: mounika.bavisetti@gmail.com
}

\begin{abstract}
Earthquake affected structures, mostly failure occur at beam column joints (BCJ). BCJs are categorized according to their geometrical grouping as Interior, Exterior, and Corner joints. Exterior beam column joint (i.e., terminating the beam on one of the column faces) was the most vulnerable one with respect to the plane of loading. The present study aims at ductility behaviour of exterior BCJ with conventional reinforcement using the code IS 456-2000 and with special confining reinforcement using the Code IS 13920-2016. Four number of beam-column joint specimens are considered in which the first one is detailed as per IS 456-2000, the second one as per IS 13920 2016 and the other two with 50\% and 30\% reduction of shear reinforcement was provided while compared with the first specimen. It is mainly to satisfy the strong column-weak beam concept as the main parameter. The test was carried out on the loading frame with hinged conditions to the column both ends, and the load is applied at the tip of the beam. The experimental studies are proven with an analytical study carried out by finite element model by using ANSYS and disparate parameters are assessed both experimentally and analytically.
\end{abstract}

Keywords: Ductility, Exterior joints, Monotonic loading, Shear reinforcement, Strong column weak beam concept

\section{Introduction}

In early days, the study of Beam-Column Joint (BCJ) is to only satisfy the anchorage reinforcement. After that, a lot of research has been recorded on parameters like detailing of reinforcement, the strength of concrete and loading pattern etc. In limit state design, the aim of BCJ is to resist the combination of worst load to provide enough strength. In earthquake resistant structures, the reinforced concrete frames are to be designed based on strong column-weak beam concept. In BCJ, yielding of beam occurred at high displacement such that beam was designed to be failed in shear or flexure. In this study, the effect of shear reinforcement in the beam has been examined experimentally and analytically.

Three modes of failures in beam-column joint listed as follows:

- Joint shear failure

- Anchorage failure

- Bond failure

When an earthquake occurs a large amount of shear force develops, so that shear stress at the joint should be reduced to eliminate joint shear failure. To achieve that, development length of the bar in beam should be increased but it creates a problem in the joint because there is a pressure of existing transverse members. If development length is not enough i.e., if it is less, anchorage failure can also occur. As shown in Fig. 1, diagonal cracks are developed due to the shear force acting at the joint. The bars bent away from the joint results in poor detailing whereas bars passing through each other results in satisfactory detailing.
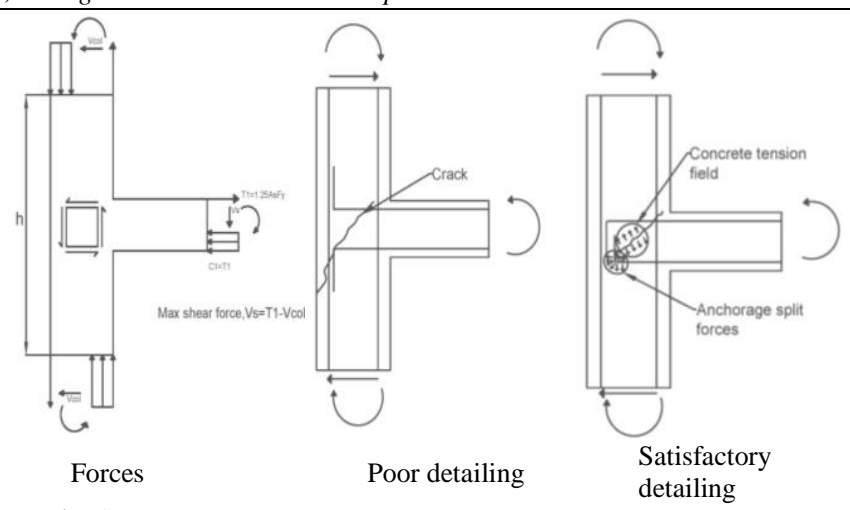

Fig. 1 Forces acting on the exterior BCJ (Courtesy: IITK-GSDMAEQ31-V1.0)

The specimen having less transverse reinforcement produces maximum shear and the deformation is more for corner and exterior joints. Hence, the shear strength of the joint will be high for the specimens with special confinement [1]. Using cross inclined bars in BCJ is a feasible solution for increasing their shear capacity and produces more strength under statically applied load. The load carrying capacity increases by providing cross diagonal reinforcement. Stiffness and ductility of joint capacity also increase in both upward and downward loading conditions [2]. The study on the load-displacement behaviour of BCJs in ABAQUS gives realistic behaviour than ANSYS which is subjected to monotonic loading and proposes the clear understanding of reinforced concrete subassemblies in ABAQUS [3]. The displacement and minimum \& maximum stress vary non-linearly with the stiffness of the structure. For fixed support condition, displacement and stress values are minimum as compare to hinge support condition. The behaviour of corner beam-column joint is distinct than that of the 
exterior beam-column joint [4]. Crack capacity was controlled by $\mathrm{X}$-cross bar plus U-bar which shows lesser cracks with increasing in seismic performance. Congestion of reinforcement is also reduced by providing $\mathrm{T}$-headed bar in the joint core area [5].To assess the seismic behaviour of BCJ, parameters like ductility, stiffness degradation, and energy absorption are studied [6]. Selfcompacting concrete and steel fibers are used to overcome the congested reinforcement present in the joint core. Due to this, the strength and ductility are improved in the joint [7]. Beam flexural type of failure occurs with joint shear reinforcement whereas joint shear failure occurs without joint shear reinforcement [8]. In wide beam-column connections, if the dimension of the beam changes then its impacts on the capacity of the structure as plastic energy dissipation. Due to increase in the width of the beam, the resistance of the beam against crack improves significantly [9]. In case of the base shear capacity of the building, the increase in the reinforcement in column joint has a negligible impact when compared to the beam reinforcement at joint [10].

\section{Research significance}

A broad research has been done to study the behaviour of beamcolumn joints from the past few decades. Though the behavioral studies on the beam-column joint are predominant, the failure of structures has been increasing day by day. The main objective of this study is considering the strong column-weak beam concept because the collapse of a beam is a localized failure rather than the collapse of a column results in globalized failure. The behaviour of ductility joint compared to conventional and reduction of shear reinforcement is studied. The design was done as per revised code of IS 13920-2016 [11] and IS 456-2000 [12]. At one-third distance from joint zero moments are formed, so hinges are considered as support conditions

\section{Experimental program}

The dimensions of all specimens are same are shown in Table 1.Out of four specimens one is conventional designated as control specimen (CS), specimen provided with special confinement designated as ductility specimen (DS) and the other two are with 50\% and $30 \%$ shear reinforcement reduction designated as beam weak in shear 1 (BWS1) and beam weak in shear 2 (BWS2).

Table 1: Dimensions of all specimen

\begin{tabular}{|c|c|c|c|c|c|}
\hline \multicolumn{2}{|c|}{ Column dimensions(mm) } & \multicolumn{3}{c|}{ Beam dimensions(mm) } \\
\hline Length & Width & Depth & Length & Width & Depth \\
\hline 1000 & 150 & 200 & 370 & 150 & 200 \\
\hline
\end{tabular}

As per IS 10262-2009 [13], design mix calculations of the M25 grade was made. Ordinary Portland cement of 53 Grade, the coarse aggregate of size $20 \mathrm{~mm}$ and fine aggregate confirming to zone-II was used. The specific gravity of cement is 3.15 , fine aggregate is 2.32 and for coarse aggregate is 2.78 . Target mean strength for an M25 grade is $31.6 \mathrm{~N} / \mathrm{mm}^{2}$.

\subsection{Reinforcement details of all specimens}

The reinforcement detailing for four specimens is according to IS 456-2000. The reinforcement details are shown in Table 2 and Table 3. Reinforcement details are shown in Fig. 2 to Fig.5.
Table 2: Reinforcement detailing of beam

\begin{tabular}{|c|c|c|c|c|c|c|c|}
\hline \multirow[b]{2}{*}{ S.no } & \multirow[b]{2}{*}{ Specimen } & \multicolumn{3}{|c|}{ Longitudinal reinforcement } & \multicolumn{3}{|c|}{$\begin{array}{c}\text { Transverse reinforce- } \\
\text { ment }\end{array}$} \\
\hline & & $\begin{array}{c}\text { No of } \\
\text { bars \& } \\
\text { Dia }\end{array}$ & $\begin{array}{c}\mathrm{A}_{\mathrm{st}} \\
\left(\mathrm{mm}^{2}\right)\end{array}$ & $\mathrm{P}_{\mathrm{t}}(\%)$ & $\begin{array}{c}\text { No } \\
\text { of } \\
\text { bars } \\
\& \\
\text { Dia }\end{array}$ & $\begin{array}{c}\mathrm{A}_{\mathrm{st}} \\
\left(\mathrm{mm}^{2}\right)\end{array}$ & $\mathrm{P}_{\mathrm{t}}(\%)$ \\
\hline 1 & $\mathrm{CS}$ & \multirow{4}{*}{$\begin{array}{c}\text { Top r/f } \\
3-16 \\
\text { mm } \\
\text { Bottom } \\
\text { r/f 2- } \\
12 \mathrm{~mm}\end{array}$} & \multirow{3}{*}{603.18} & \multirow{3}{*}{0.02} & $\begin{array}{l}5-8 \\
\mathrm{~mm}\end{array}$ & 251.3 & 0.0084 \\
\hline 2 & DS & & & & $\begin{array}{l}9-8 \\
\mathrm{~mm}\end{array}$ & 452.34 & 0.015 \\
\hline 3 & BWS-1 & & & & $\begin{array}{l}3-8 \\
\mathrm{~mm}\end{array}$ & 150.78 & 0.005 \\
\hline 4 & BWS-2 & & 226.19 & 0.0075 & $\begin{array}{l}2-8 \\
\mathrm{~mm}\end{array}$ & 100.52 & 0.0035 \\
\hline
\end{tabular}

Table 3: Reinforcement detailing of column

\begin{tabular}{|c|c|c|c|c|c|c|c|}
\hline \multirow[b]{2}{*}{$\begin{array}{l}\text { S. } \\
\text { no }\end{array}$} & \multirow[b]{2}{*}{ Specimen } & \multicolumn{3}{|c|}{$\begin{array}{c}\text { Longitudinal reinforce- } \\
\text { ment }\end{array}$} & \multicolumn{3}{|c|}{ Transverse reinforcement } \\
\hline & & $\begin{array}{c}\text { No of } \\
\text { bars \& } \\
\text { Dia }\end{array}$ & $\begin{array}{c}\mathrm{A}_{\mathrm{st}} \\
\left(\mathrm{mm}^{2}\right)\end{array}$ & $\mathrm{P}_{\mathrm{t}}(\%)$ & $\begin{array}{c}\text { No of } \\
\text { bars \& } \\
\text { Dia }\end{array}$ & $\begin{array}{c}\mathrm{A}_{\mathrm{st}} \\
\left(\mathrm{mm}^{2}\right)\end{array}$ & $\mathrm{P}_{\mathrm{t}}(\%)$ \\
\hline 1 & CS & \multirow{4}{*}{$\begin{array}{l}4-16 \\
\mathrm{~mm}\end{array}$} & \multirow{4}{*}{804.24} & \multirow{4}{*}{0.027} & $\begin{array}{l}7-8 \\
\mathrm{~mm}\end{array}$ & 351.85 & 0.018 \\
\hline 2 & DS & & & & $\begin{array}{l}15-8 \\
\mathrm{~mm}\end{array}$ & 753.98 & 0.025 \\
\hline 3 & BWS-1 & & & & $\begin{array}{l}7-8 \\
\mathrm{~mm}\end{array}$ & 351.85 & 0.018 \\
\hline 4 & BWS-2 & & & & $\begin{array}{l}7-8 \\
\mathrm{~mm}\end{array}$ & 351.85 & 0.018 \\
\hline
\end{tabular}

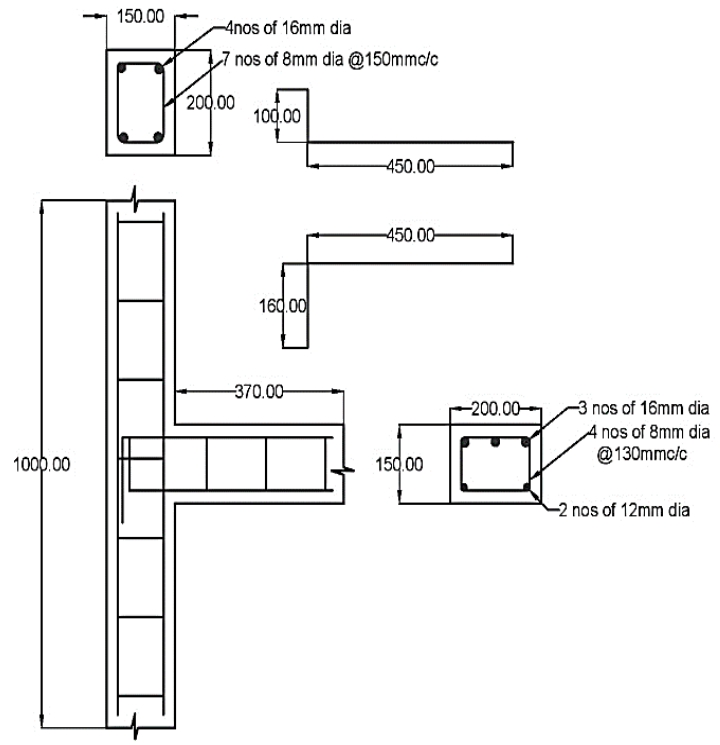

Fig. 2 Conventional specimen as per IS: 456-2000 


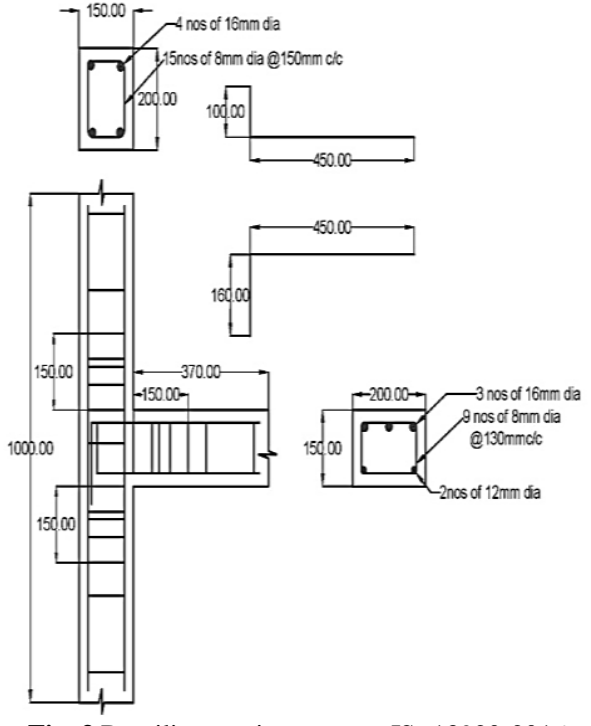

Fig. 3 Ductility specimen as per IS: 13920-2016
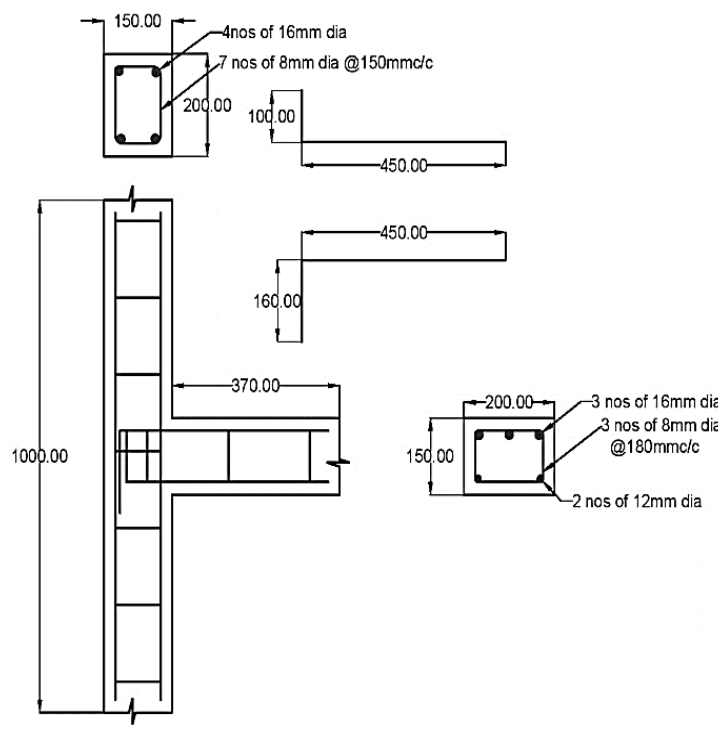

Fig. 4 Beam weak in shear-1 specimen

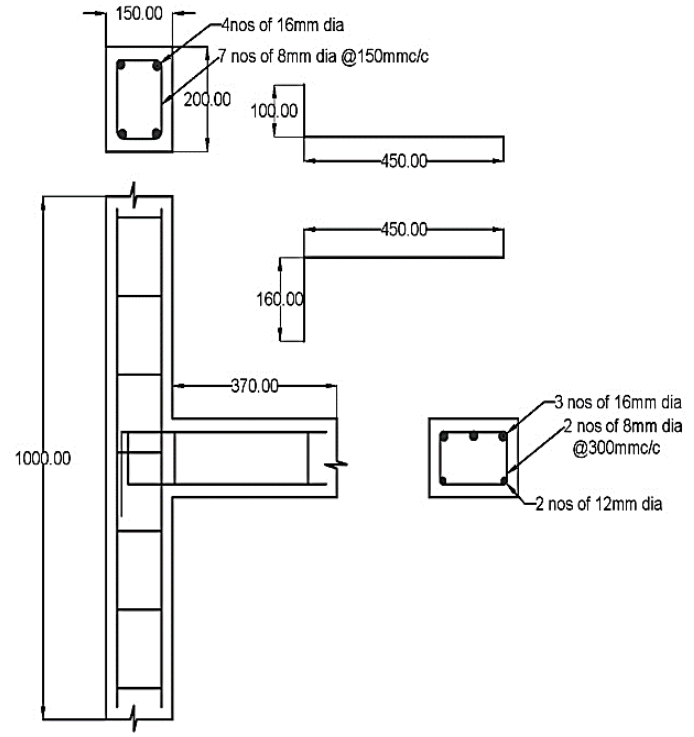

Fig. 5 Beam weak in shear-2 specimen

\subsection{Test set up}

Hinge supports are used as boundary conditions at both ends of the column. They are fabricated based on loading frame setup and specimen dimensions in which top fin plates are adjustable for any depth of the column. For column axial load, a hydraulic jack is kept at one end of the column. Hinge supports and jack are shown in Fig. 6.
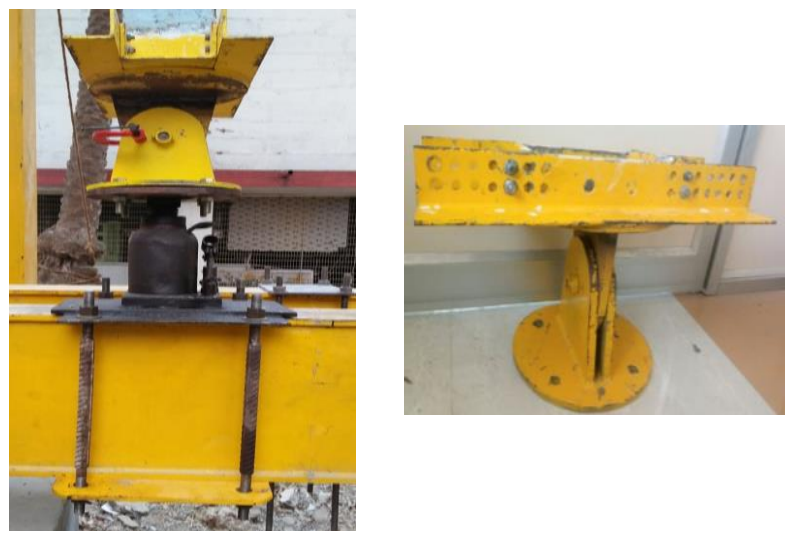

Fig. 6: Hydraulic jack and Hinge support

The specimens were tested on the loading frame having a capacity of 50 tones hydraulic jack is applied to the tip of the beam. Hinge supports were attached to the column ends with C-clamps which are used for tightening purpose. For column axial load, a hydraulic jack is placed by using a plate which was anchored to the girder. By using a hydraulic jack of capacity 75 tons, a constant axial load of 2 tonnes was applied from the bottom of the column. The deflection was measured at the point of application of the load at the bottom end of the beam by using Linear Variable Differential Transducers (LVDTs). All the data recorded by a data logger which is connected to a computer. Fig.7 shows the test set up of the specimens.

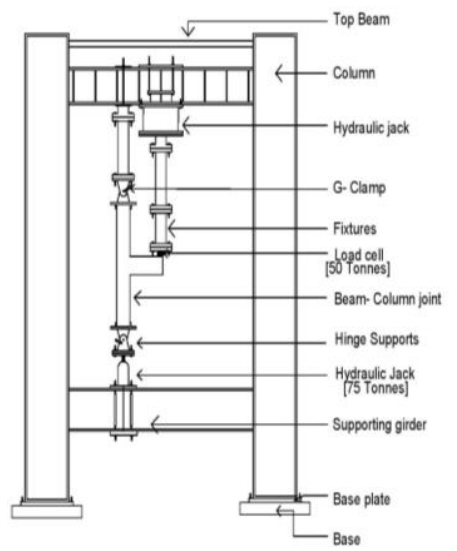

(a) Schematic diagram

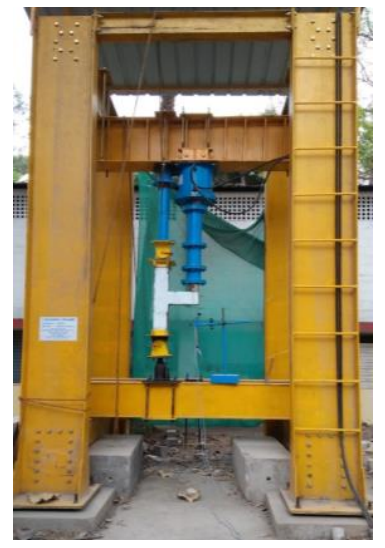

(b) Actual test set up
Fig. 7 Test setup of a loading frame

\section{Analysis of beam column joint}

Considering the joint shear failure mode as the main parameter, non-linear finite element analysis of RC beam-column connection is analyzed using ANSYS. The solid 65 is used to model the concrete element consists of eight nodes whereas link 188 is used to model the reinforcement. This referred to a uniaxial tensioncompression element which is having three degrees of freedom at each node such as translations occurred in $\mathrm{x}, \mathrm{y}$ and $\mathrm{z}$ directions. Real constants are not considered for solid 65 elements since there is no rebar data. For link180, the cross-sectional area of rebar is 
considered. Linear isotropic materials are considered for concrete and steel. The elastic modulus of concrete is $0.25 \mathrm{e} 5 \mathrm{MPa}$ and for steel $2 \mathrm{e} 5 \mathrm{MPa}$. The Poisson's ratio for concrete is 0.15 and for steel is 0.3.The compressive strength of concrete is $25 \mathrm{MPa}$ and yield stress of steel is 500MPa.Build the geometry of the specimen in pre-processing considering the dimensions of the $\mathrm{BCJ}$ and meshing is done for all the elements with $40 \mathrm{~mm}$ mesh size as shown in Fig. 8. From experimental data, load at which failure occurs were considered and applied it on the tip of the beam nodes as a point load. For column, a constant axial load of 2 tonnes was applied. Pinned supports or hinged conditions were used for both ends of the column such that $\mathrm{X}$-direction is released whereas $\mathrm{Y}$ and $\mathrm{Z}$ directions are constrained.

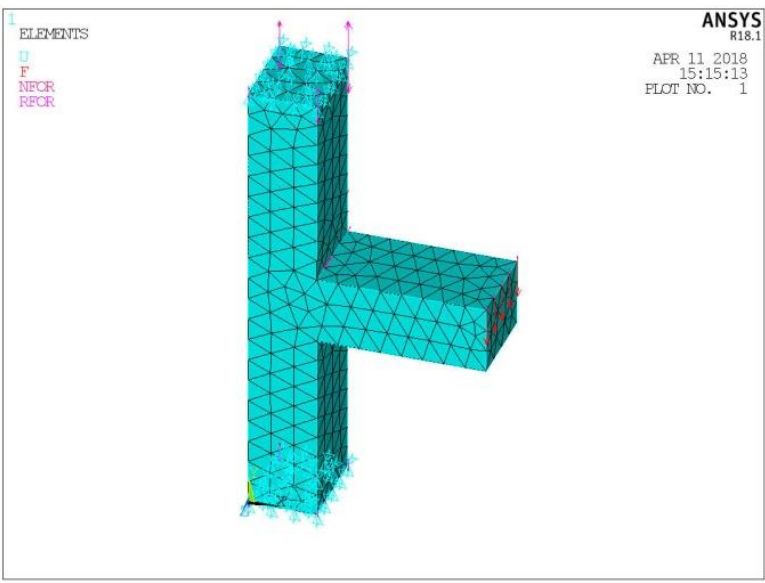

Fig. 8 Meshed model with loads and boundary conditions

\section{$5 \quad$ Results and discussion}

The experimental and numerical results have been discussed in this section.

\subsection{Experimental Outcomes}

The observations during the test are concisely presented in the form of load vs. deflection, stiffness degradation, normalized graphs and crack pattern for all specimens are described in this section.

\subsubsection{Load Vs Deflection}

The load vs. deflection curve is drawn for all specimens in which applied load is on the vertical axis and deflection is on the horizontal axis as shown in Fig. 9. At the initial stage of testing the displacement was zero. A gradual decrease in the load was observed when it reaches the peak load. It clearly gives that the maximum load carrying capacity for DS is significant compared to other specimens and exhibited better results. The maximum load and the corresponding deformation for all the specimens are shown in Table 4.

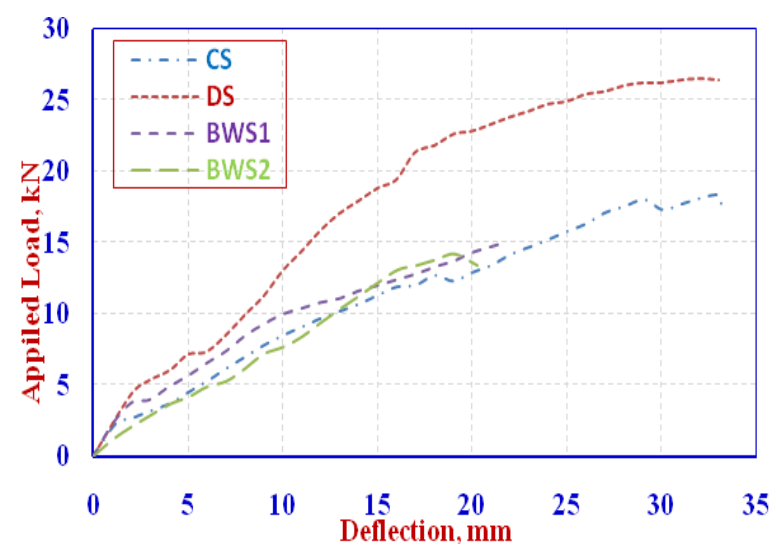

Fig. 9: Load vs. Deflection

Table 4: Maximum load and deflection

\begin{tabular}{ccc}
\hline Specimen & Load $(\mathbf{k N})$ & Deflection $(\mathbf{m m})$ \\
\hline CS & 18.3 & 33.14 \\
DS & 26.6 & 32.02 \\
BWS-1 & 14.9 & 21.51 \\
BWS-2 & 14.2 & 19.06 \\
\hline
\end{tabular}

\subsubsection{Stiffness Degradation}

The graph is drawn for stiffness (load required to cause unit deflection) on vertical axis and deflection on the horizontal axis as shown in Fig. 10. The maximum stiffness is obtained for DS is higher when compared to the other three specimens. The CS and BWS specimens have very low stiffness. The stiffness degradation is high for BWS specimens and very low for DS. Table 5 shows maximum stiffness for the corresponding deflection.

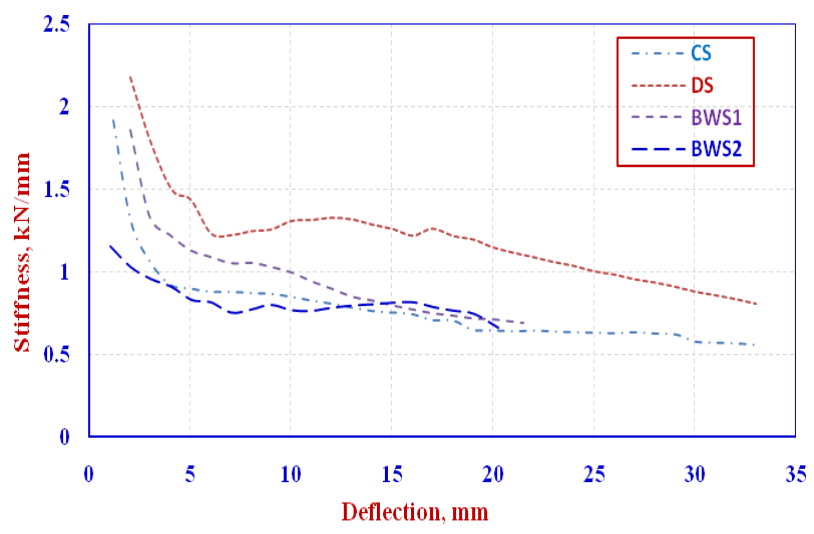

Fig. 10 Stiffness vs Deflection

Table 5: Maximum Stiffness and deflection

\begin{tabular}{ccc}
\hline Specimen & Stiffness $(\mathbf{k N} / \mathbf{m m})$ & Deflection $(\mathbf{m m})$ \\
\hline CS & 0.554 & 33.14 \\
DS & 0.830 & 32.02 \\
BWS-1 & 0.693 & 21.51 \\
BWS-2 & 0.745 & 19.06 \\
\hline
\end{tabular}

\subsubsection{Normalisation graph}

Fig. 11 shows that normalized graph of shear strength $\left(\mathrm{P}_{\mathrm{u}} / \mathrm{f}_{\mathrm{ck}} \mathrm{bd}\right)$ on y-axis and drift ratio (deflection with respect to its length) on the x-axis. Hence the normalized shear strength for DS is very high which gives better results. Due to its ductility nature, it has more shear strength. Where other specimens namely CS is satisfactory and BWS specimens are below the CS and DS. Table 6 shows maximum shear strength and drift ratio for all the specimens. 


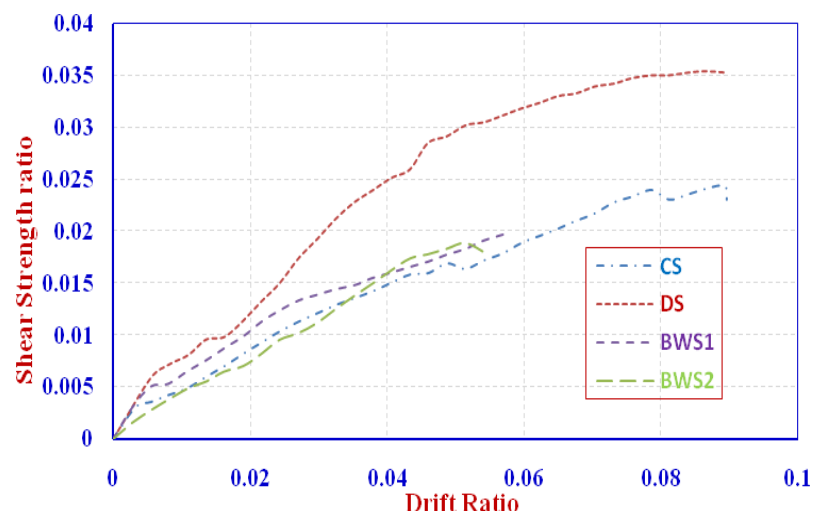

Fig. 11 Shear strength vs. Drift ratio

Table 6: Maximum Shear strength vs Drift ratio

\begin{tabular}{ccc}
\hline Specimen & $\begin{array}{c}\text { Shear } \\
\text { strength }\end{array}$ & $\begin{array}{c}\text { Drift } \\
\text { ratio }\end{array}$ \\
\hline CS & 0.02440 & 0.0893 \\
DS & 0.03533 & 0.0865 \\
BWS-1 & 0.01986 & 0.0581 \\
BWS-2 & 0.01893 & 0.0515 \\
\hline
\end{tabular}

\subsubsection{Crack pattern}

In all the specimens crack was propagated at joint region only. Initially, a crack develops at beam to column interface and propagates from joint to column. Mainly shear cracks are developed in the joint region for shear reduction specimens. Among all the specimens, a specimen with ductile reinforcement gives better performance when compared to CS, BWS-1 and BWS-2. Fig. 12 shows the crack pattern of all the specimens.

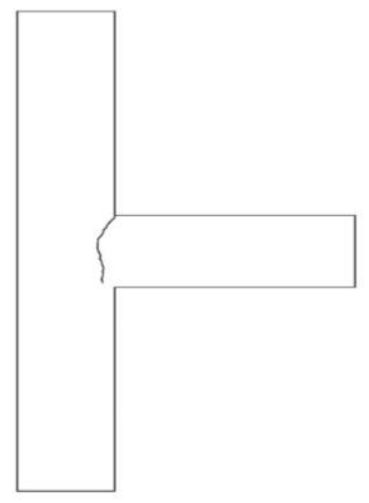

(a) Coneventional Specimen

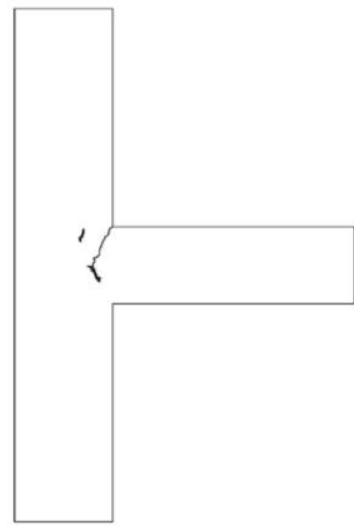

(c) Beam weak in shear-1

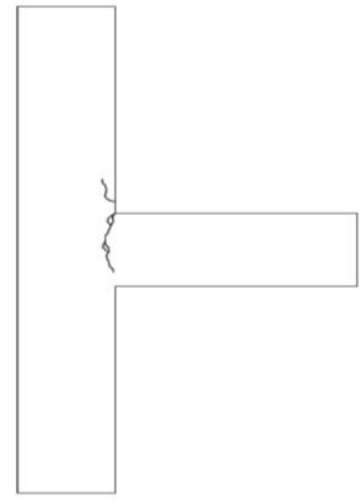

(b) Ductile Specimen

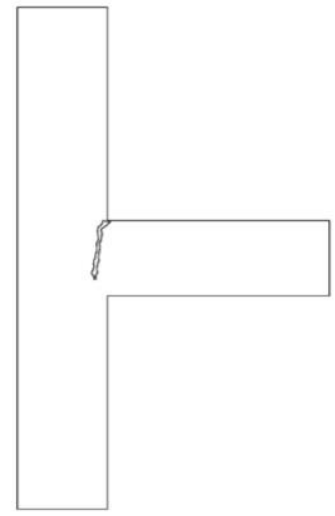

(d) Beam weak in shear-2
Fig. 12: Crack pattern for all specimens

\subsection{Numerical Outcomes}

Results from analytical studies are observed and discussed in this section. All BCJ specimens such as CS, DS, BWS-1 and BWS-2 are modeled and analyzed with parameters like deformation, stress intensity and stress vector are observed.

\subsubsection{Deformed shape}

Fig. 13 to Fig. 16 shows the deformed shapes of all specimens with respect to the undeformed model. Considering the respective experimental load, all specimens are analyzed. The shear reduction specimens namely BWS-1 and BWS-2 show significant deflection and hinge action was encountered. Hence, out of four specimens, ductile specimen shows less deflection and it is preferable.

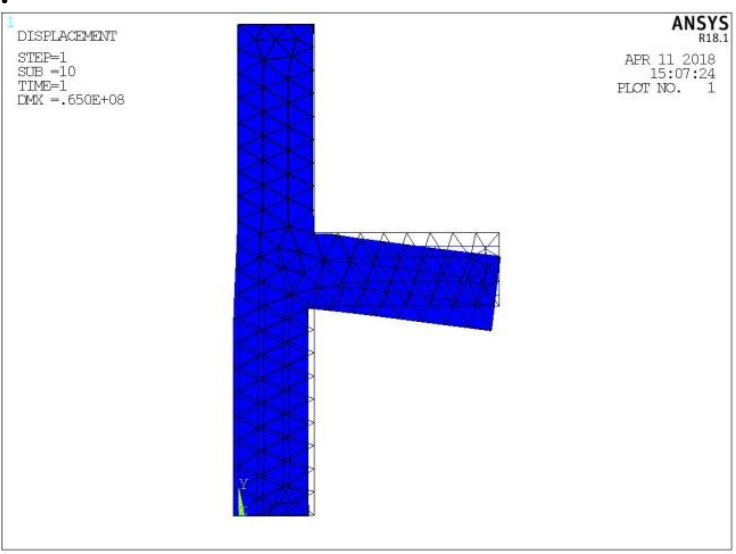

Fig. 13: Deformed shape of CS

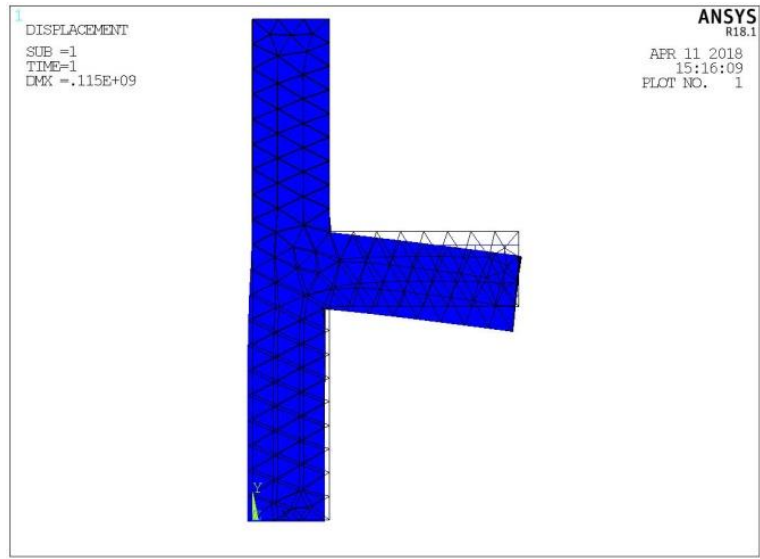

Fig. 14 Deformed shape of DS

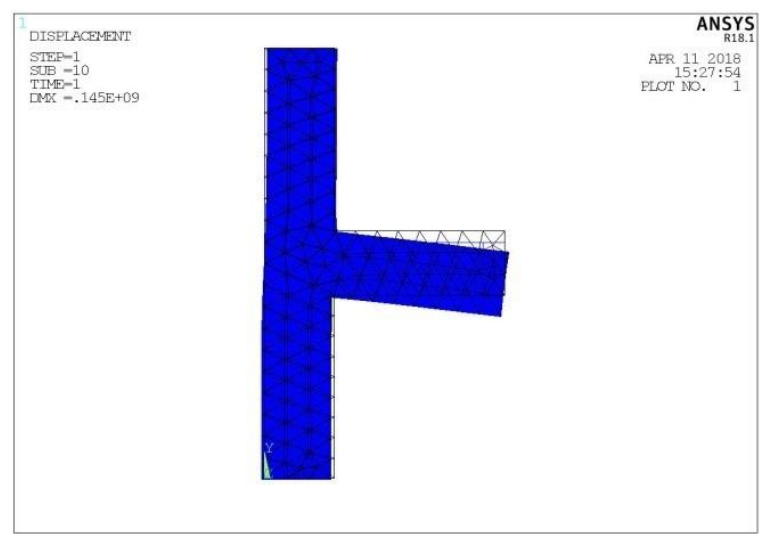

Fig. 15 Deformed shape of BWS-1 


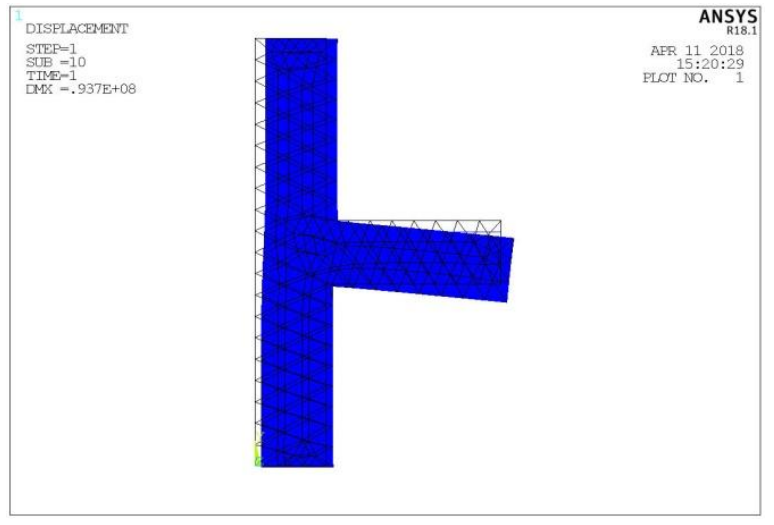

Fig. 16 Deformed shape of BWS-2

\subsubsection{Stress intensity of all specimens}

The Stress intensity depends on the maximum stress induced on the structure. For all specimens maximum stress is obtained at joint region only. A large amount of stress is developed at the column to beam interface and in the rear side of the shear reduction specimens. For BWS-2, high stress intensity is developed on the top side of the column. Stress intensity for DS is very less. Fig. 17 to Fig. 20 shows stress intensity of all specimens.

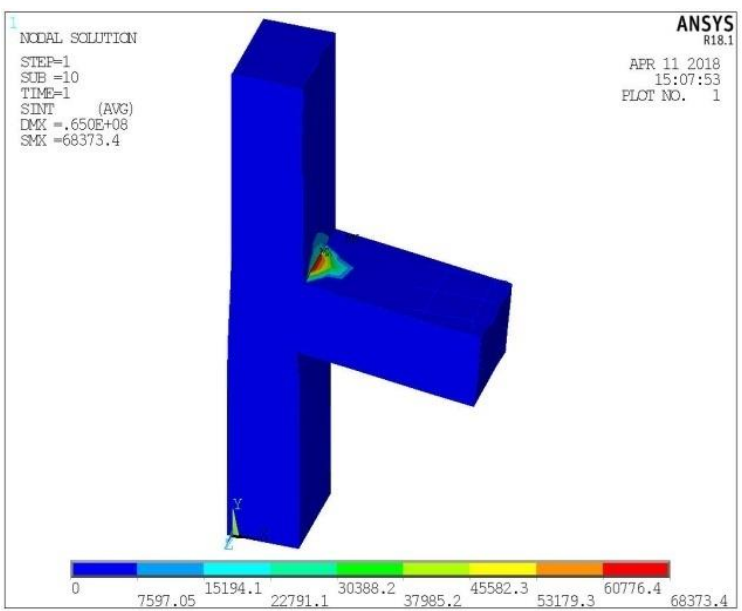

Fig. 17 Stress intensity of CS

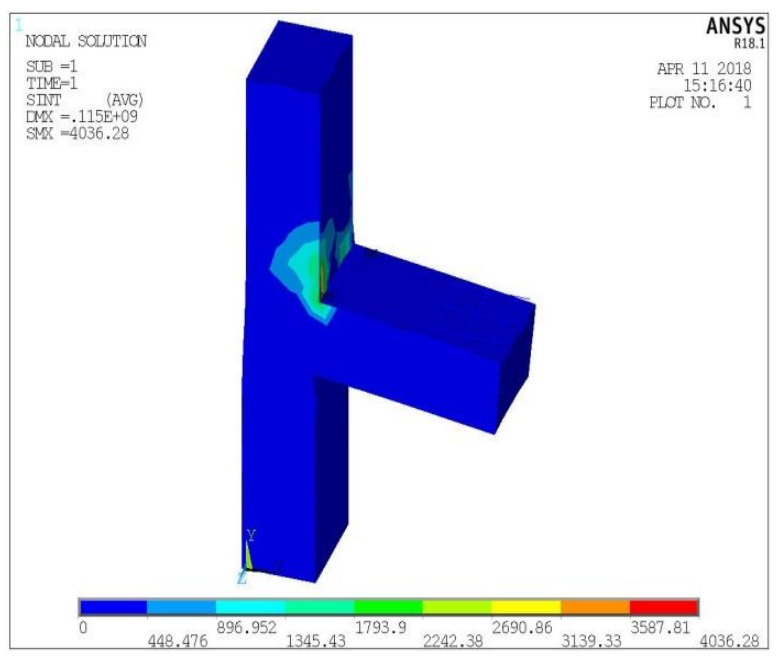

Fig. 18 Stress intensity of DS

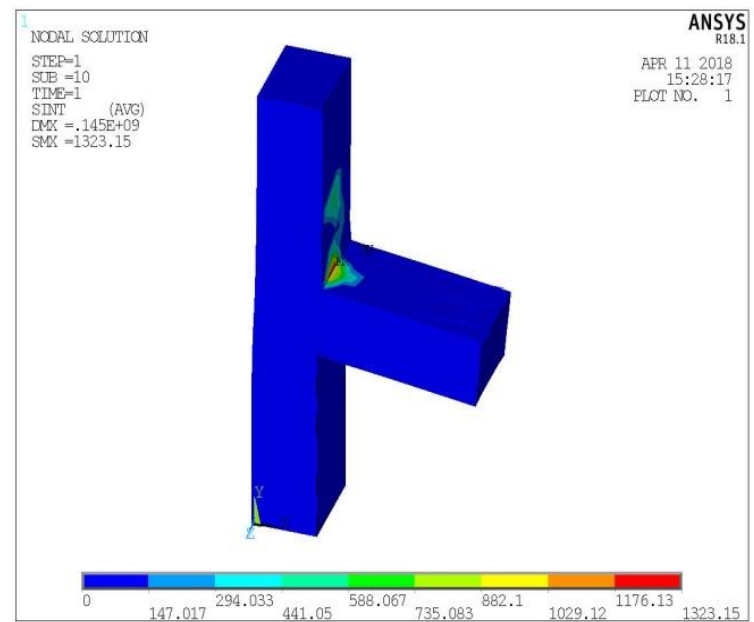

Fig. 19 Stress intensity of BWS-1

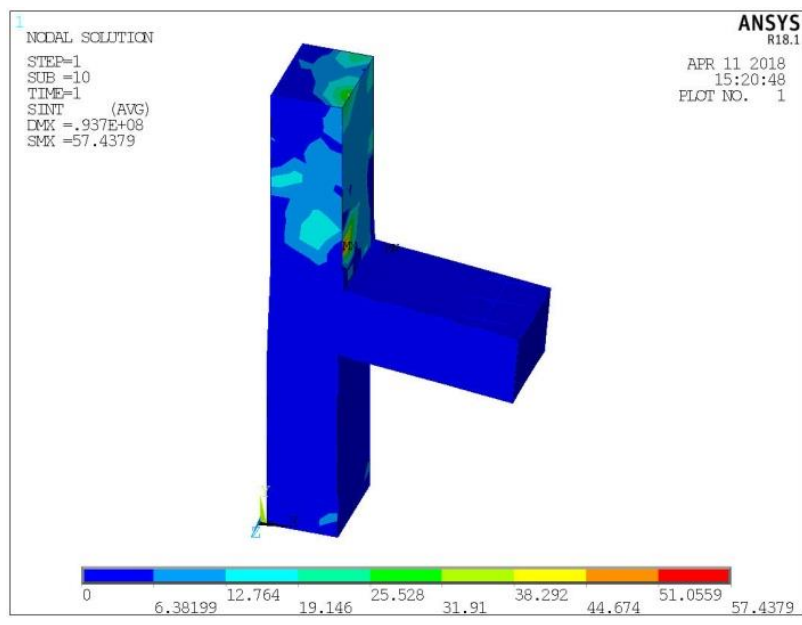

Fig. 20 Stress intensity of BWS-2

\subsubsection{Stress vector of all specimens}

The stress vector is the force per unit surface. It is nothing, but stress develops and travels from that point. The stress vector of all specimens is shown in Fig. 21 to Fig.24. Mostly stress develops in the joint region but BWS specimens have more stress in the column and in joint region and concrete crushes at that region because it undergoes tension where stress is high. Due to hinges, column displaces and stress vector (i.e., the direction of force) is shown and develops a crack from that region. The BWS specimens have high stress vectors developed in the joint.

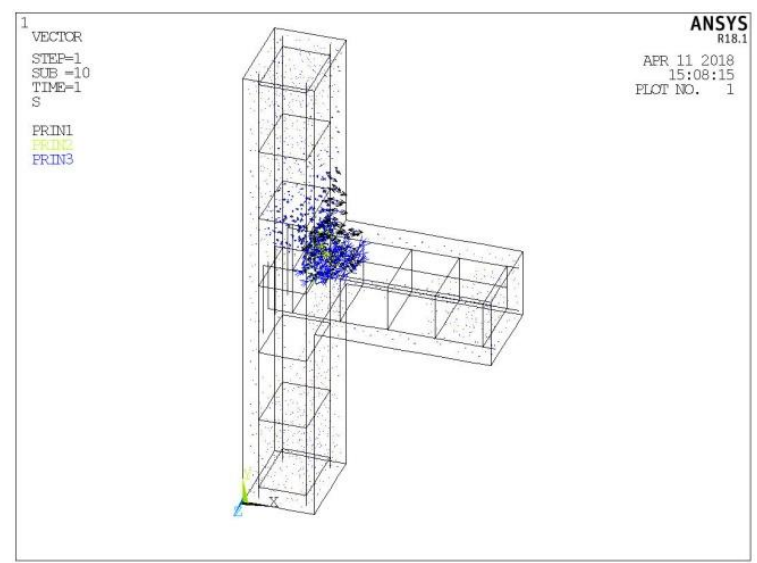

Fig. 21 Stress vector of CS 


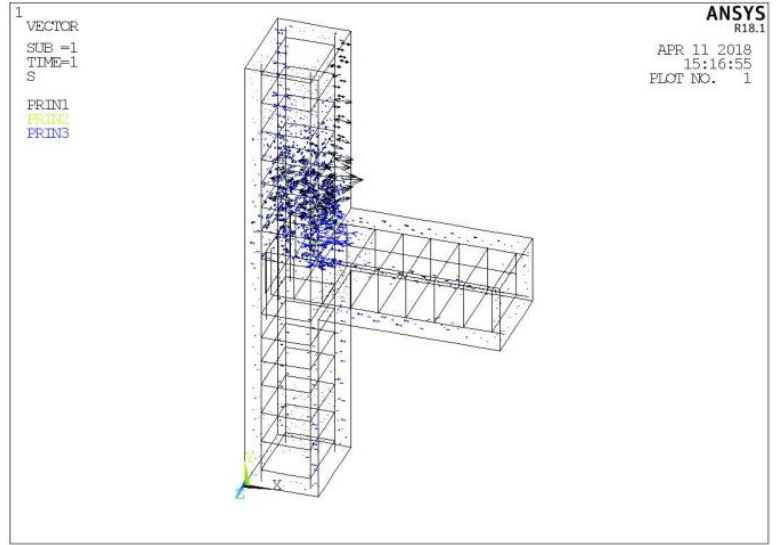

Fig. 22 Stress vector of DS

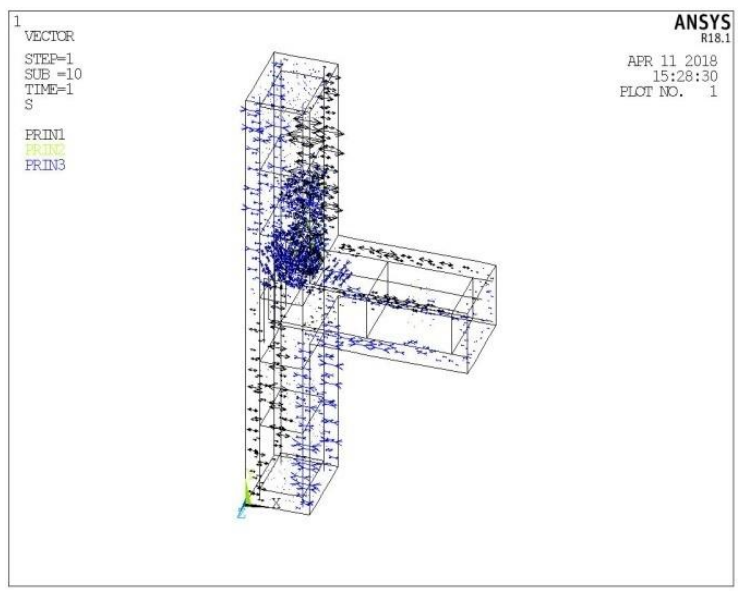

Fig. 23 Stress vector of BWS-1

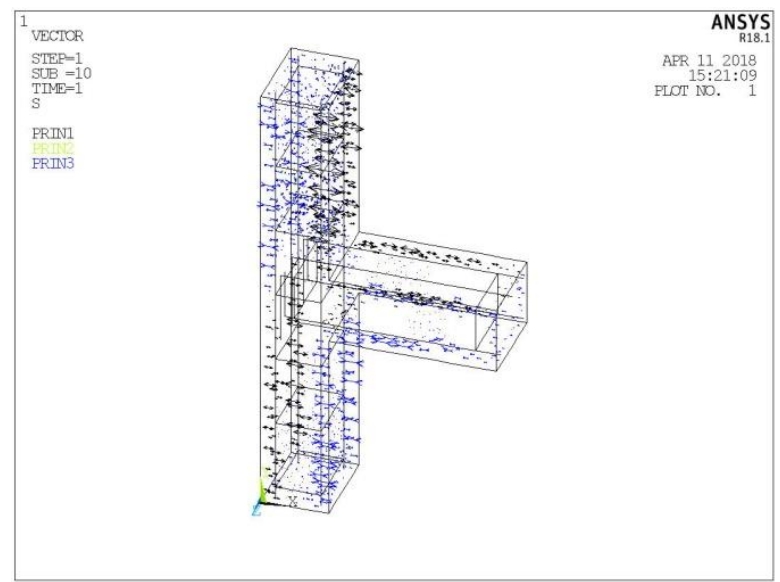

Fig. 24 Stress vector of BWS-2

\section{Conclusions}

In this study, the performance of exterior beam-column joint with conventional, unconventional and confinement reinforcement detailing was observed. The following conclusions are drawn from experimental and analytical results.

- All BCJ specimens are failed at the joint under monotonic loading.

- The failure occurred at joint, even the beam is deficient with shear reinforcement.

- The shear cracks for BWS specimens and flexural cracks for CS and DS are developed at the joint.

- As the load increases deflection also increases for all the specimens. Therefore, DS have high load carrying ca- pacity under the same deflection when compared to CS and the other two specimens.

- The stiffness of all the specimens is gradually decreased with increasing load. The stiffness degradation is high for BWS-2 and low for DS.

- It can be observed that for all the specimens, shear strength increases with increasing drift ratio. Due to its ductility behaviour of DS has shown significant shear strength.

- The beam is deflected due to hinge action in ANSYS analysis.

- The maximum and minimum stress intensity and crack/crush occurred at the joint region in beam column joint.

- The stress intensity is high for BWS specimens and less for DS specimen so that failure occurred in joint in case of CS and BWS specimens.

\section{References}

[1] Prabu N \& Kandasmy S, "Study on Behavior of RCC Beam Column Joint with Special Confinement Subjected to Static Loading Numerical Investigation", International Journal of Innovative Research in Engineering \& Management (IJIREM), Vol.3, No1, (2015), pp.186190.

[2] Tiwary AK \& Mohan M, "Strengthening of Exterior Beam Column Joint with Modified Reinforcement Technique", IOSR Journal of Mechanical and Civil Engineering (IOSR-JMCE), Vol.1, N0.6, (2014), pp.32-37.

[3] Chaudhari SV, Mukane KA \& Chakrabarti MA, "Comparative study on Exterior RCC Beam Column Joint Subjected to Monotonic Loading", International Journal of Computer Applications, Vol.102, No.3, (2014), pp.34-39.

[4] Patil SS, Konapure CG \& Manakari SS, "A Study of R. C. C. Beam Column Junction Subjected to Quasi-Static (Monotonic) loading", IOSR Journal of Mechanical and Civil Engineering (IOSR-JMCE), Vol.6, No.5, (2013), pp.149-158.

[5] Gopal SR \& Prabhavathy S, "Seismic Behavior of Exterior BeamColumn Joint using Mechanical anchorage under Reversal loading”, IJST Transactions of Civil Engineering, Vol.38, No.C2, (2014), pp.345-358.

[6] Rajaram P, Murugesan A \& Thirugnanam GS, "Experimental Study on behavior of Interior RC Beam Column Joints Subjected to Cyclic Loading", International Journal of Applied Engineering Research, Dindigul, (2010), Vol.1, No.1, pp.49-59.

[7] Manjunatha K, Nambiyanna B \& Prabhakara R, "Ductility Behaviour of External SFRSCC Beam Column Joint- An Experimental Study", International Journal of Innovative Research in Science, Engineering and Technology, Vol.5, No.11, (2016), pp.19837-19844.

[8] Asran AG, Hassan HE \& Sabryfayed, "Numerical Investigation of RC Exterior Beam Colum Connections under Monotonic Loads", IOSR Journal of Mechanical and Civil Engineering (IOSR-JMCE), Vol.13, No.1, (2016), pp.60-6.

[9] Elahe E \& Khosro F, "Behavior of reinforced concrete interior wide beam-column connections under lateral loading: A finite element study", International Journal of Engineering and Technology (IJET), Vol.9, No.3, (2017), pp.2559-2570.

[10] Rao PK, Balaji KVGD, Raju GSSSV \& Rao S, "Effect of Increase of Reinforcement Near Beam-Column Joints in Performance-Based Design of Low-Rise Buildings", International Journal of Engineering and Technology (IJET), Vol.9, No.3, (2017), pp.2605-2618.

[11] IS13920:2016, Ductile Design and Detailing of Reinforced Concrete Structures Subjected to Seismic Forces - Code of Practice, Bureau of Indian Standards, New Delhi.

[12] IS 456:2000, Indian Standard code of Practice- Plain and Reinforced Concrete, Fourth Revision, Bureau of Indian standards, New Delhi.

[13] IS 10262 (2009): Guidelines for concrete mix design proportioning [CED 2: Cement and Concrete], Bureau of Indian Standards, New Delhi.

[14] Subramanian N \& Prakash DS, "Design of Joints in RC Structures with Particular Reference to Seismic Conditions", The Indian Concrete General, (2003). 